\title{
NATURE DAZZLES
}

\section{A Short Documentary Film}

\section{Camilo Gómez-Durán}

\section{ABSTRACT}

Bullying and violence against transitioning children and youth within the Canadian educational system still continues to be a serious cause of stress for children. This paper supports a short documentary film (29 minutes), which includes interviews with children, parents, and teachers about a weeklong program called Gender Splendour that has been held for the past seven years at The Grove Community School in Toronto. Amid workshops during a week in April, non-binary-conforming and cisgender identifying children have the opportunity to ponder, question, and defy gender stereotypes, which are prevalent in society, culture, and the media. A background of the director of the film informs his trajectory as an activist communicator. In addition, some of his inspirational sources are included. Notions playing in the documentary related to activism, reflexive ethnography, performativity, and participatory dynamics, are explained. Producing a documentary on the subjects of sexuality and children surely poses difficulties related to ethics, consent, and representation, on which the author comments. 


\author{
Camilo Gómez-Durán \\ Bachelor of Arts in Anthropology \\ (Diploma with Distinction) \\ Concordia University, Montreal, 2011
}

\author{
A thesis \\ presented to Ryerson University \\ in partial fulfilment of the \\ requirements for a degree of \\ Master of Fine Arts \\ in the Program of \\ Documentary Media \\ Ryerson University
}

Toronto, Ontario, Canada

(C) Camilo Gómez-Durán 2017 


\section{Author's Declaration}

I hereby declare that I am the sole author of this thesis. This is true copy of the thesis, including any required final revisions, as accepted by my examiners.

I authorize Ryerson University to lend this thesis to other institutions or individuals for the purpose of scholarly research.

I further authorize Ryerson University to reproduce this thesis by photocopying or by other means, in total or in part, at the request of other institutions or individuals for the purpose of scholarly research.

I understand that my thesis may be made electronically available to the public. 


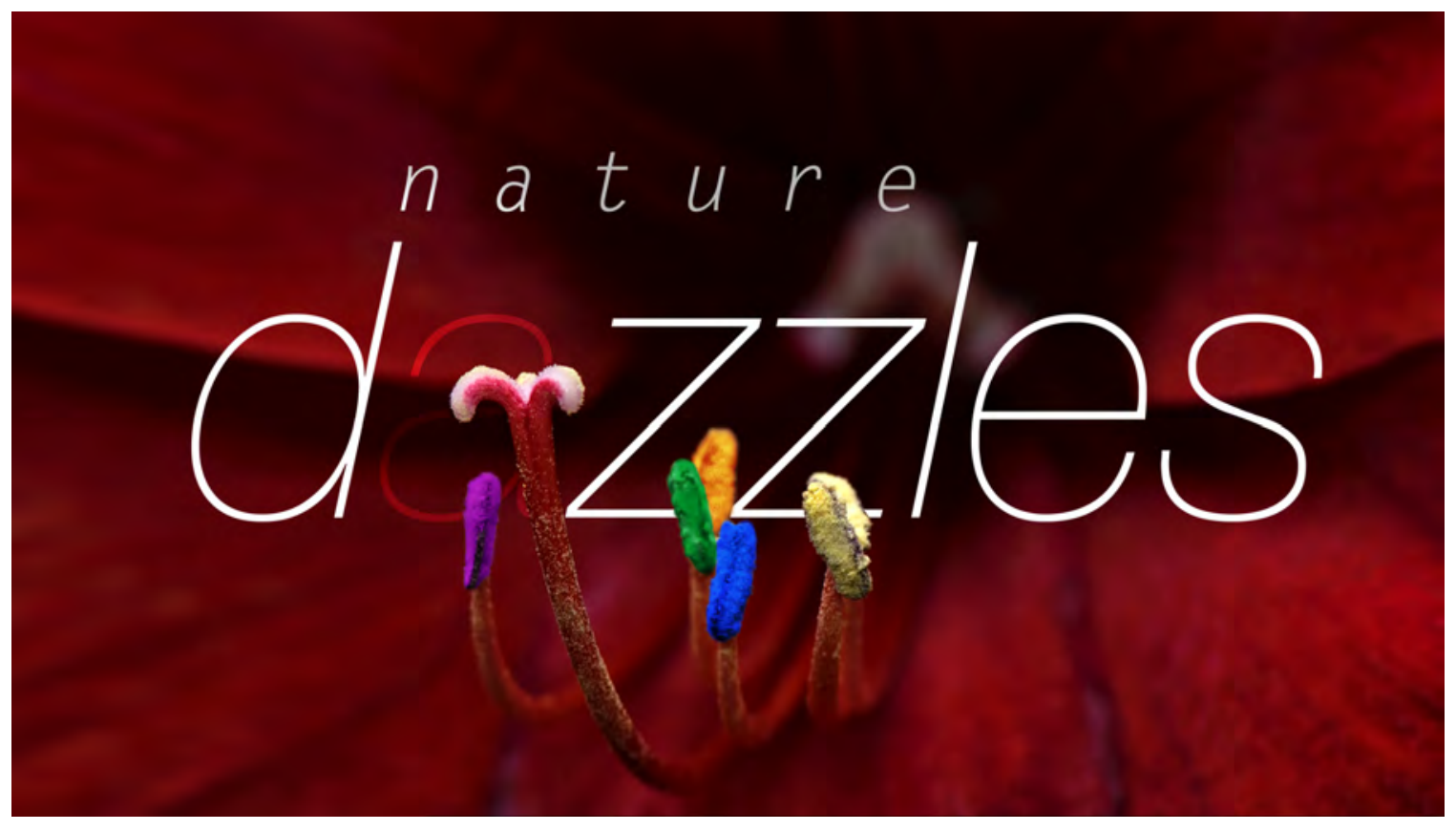

Figure 1. Promotional motion graphics by Sergio Valencia Mejía (2017) 


\section{Acknowledgments}

Without the generous and high-spirited support of my supervisor John Tarver, and the intensity and brightness of my advisor Izabella Pruska-Oldenhof, this work would have come out quite differently. Without the gentleness and wisdom of my Professor Elida Schogt, who came to my rescue in the darkest moments of explorations on a project about gender, I would have abandoned my determination to work with children, the primal transformers of society.

I would like to extend my gratitude and appreciation to the Director of the program, Katy McCormick, and to all my professors throughout these two years, in which the steep curve of learning pushed me over my own limits and limitations. These are Marc Glassman, Jason O'Hara, Gerda Cammaer, Blake Fitzpatrick, Vid Ingelevics, Richard Lachman, Don Snyder, and Sara Angelucci, from whom I received invaluable information based in humanity academics. My gratitude goes also to Alison Macleod, whose silent and dedicated administrative hard work made our lives much easier.

I would also like to extend a big thank you to Peter Conrad, Ken Robinson, Andrew Bateman, Mehrdad Ahmadpour, and Morvarid Peyda, who supported me in many ways during these two years, giving me the opportunity to learn from their skills and knowledge; to all my colleagues who bore with me and with my way-out-of-the-box ideas.

Likewise, I would like to acknowledge the transforming openness and self-giving stance of the interviewees, who conceded to being represented on the screen. It takes courage and trust. I would also like to recognize Wilma Verhagen, Velvet Lacasse, Shannon Greene, Ronda Rindone, and David Stocker, who opened their ideological space at their classrooms, so I could come and document the reach it has in the education of children. They help children to become open and aware with regard to the rainbow of gender expressions, which Canadian society has evolved to accept as more natural during recent times.

I would also like to extend my gratitude to all my friends who came up to support in so many different ways the cause of this documentary, and to those, who also showed up with a contribution during a crowd-founding campaign I put on.

I would also like to thank my friend Raul Vásquez Soto, for his tender heart, without his wisdom and deep vision this work could not have been completed. Thank you also to Sergio Valencia Mejía, his infinite patience with the motion graphics gave me so much confidence. I am also grateful to Mauricio Delgado, a generous life companion. The path of revealing adventure was also shared with Ximena Barrera, Tomislav Svoboda, and many others both in Colombia and Canada, who lovingly supported my endeavours.

Thank you also to Aram Rubenstein Gillis and David Lacoursiere, who generously contributed their music to the documentary.

Thank you also to Fiorella, who in synchronicity came out of the blue to hold my hand with conjuring humour, amid quotidian and academic struggles.

Love to my daughter Ío Gómez, who, since she came to this world, inspired me to evolve into the realms of feminism (humanism), a term that every individual should consider with respect for how women have helped make our planet an intelligently, less harsh, hopeful place. 


\section{Table of Contents}

Introduction .

1

1. Project Rationale

Gender-Based Violence

1.1 VAWG in Canada ........................................... 4

1.2 Hate Crimes Against the LGBT Community in Canada ............... 5

1.2.1 LGBT Youth ...................................... 6

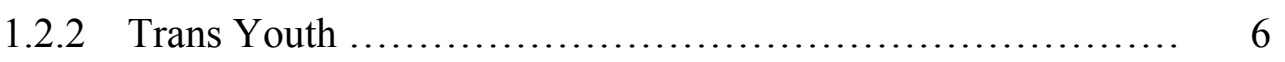

1.2.3 Aboriginal LGBT and Two Spirited Youth ................ 6

1.2.4 Violence and Harassment ............................... 7

2. Project Background

2.1 On Gender ...................................................... 10

2.2 Feminism and Gender ........................................ 10

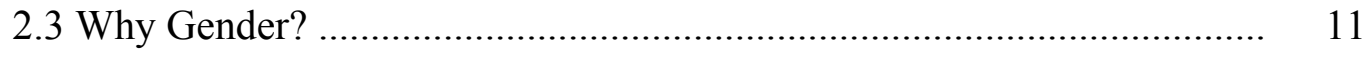

2.4 A Bumpy Road into Gender Splendour ....................................... 14

3. Methods

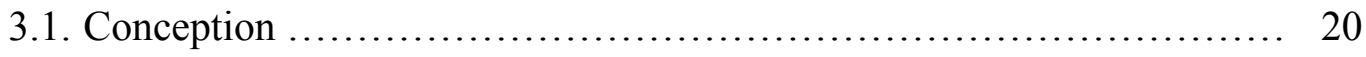

3.2. Development $\ldots \ldots \ldots \ldots \ldots \ldots \ldots \ldots \ldots \ldots \ldots \ldots \ldots \ldots \ldots \ldots \ldots \ldots \ldots \ldots, 21$

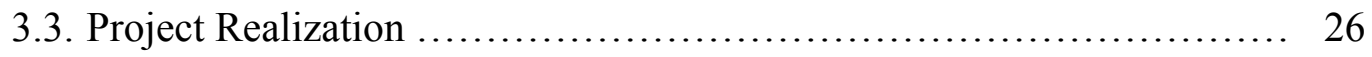

4. Documentary Relevance

4.1. Influential Films and Documentaries .......................... 30

4.2. Documentary Ethical Issues ..................................... 32

4.3. Concepts Playing Out in the Documentary ........................ 38 


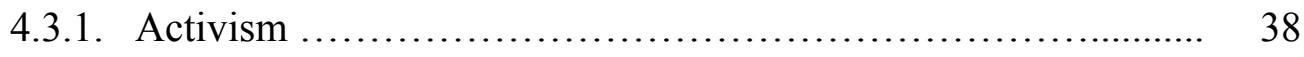

4.3.2. Reflexive Ethnography...................................... 41

4.3.3. Performativity ............................................... 42

4.3.4. Participatory Dynamics ............................................... 44

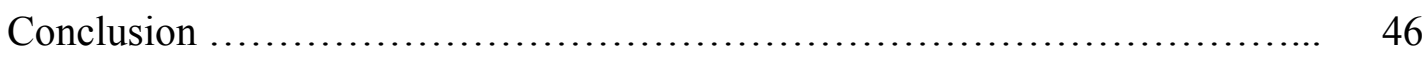

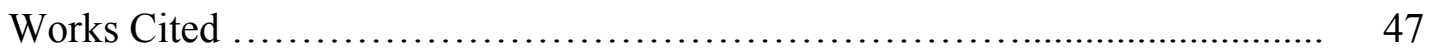




\section{List of Figures}

Figure 1: Promotional motion graphics by Sergio Valencia Mejía ............. iv

Figure 2: Lulu and Mia representing a scene on gender-based bullying ........ 8

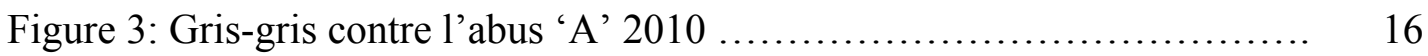

Figure 4: Sacred Flow 2013 ....................................... 34

Figure 5: Girls and Boys Who Make Boys and Girls 2013 ................ 37 


\section{Introduction}

A group of children from The Grove Community School in Toronto (TGCS) give their impressions on the workshops they attended during Gender Splendour (GS) week. The principal and teachers also comment on this program that creates a safe space for transitioning children.

Nature Dazzles is a documentary that tells an organically constructed story about the students of TGCS, who every year during a week devote themselves to activities that closely examine and challenge gender stereotypes. For this event, they are guided and encouraged by their teachers to participate in pedagogical, literary, and performance art activities, which instil in them a sense of justice regarding the rights and freedoms of the LGBT youth in Toronto.

Challenging gender stereotypes in the educational system opens new worlds to students, while giving them the ability from early childhood onwards to construct a healthy and balanced sense of gender. They are able to choose the identity that their bodies and minds tell them, while learning to match the feelings encompassed within their own sexual orientation. Being able to explore their defined, undefined, or less fixed expressions of gender could prove to be a key pedagogical practice from which each child would immensely benefit, allowing them to flourish in the essential aspects of their fluid identities and development. Most of the schools do the opposite, following "gendered patterns [...] grounded in both the formal curriculum-such as textbooks, course requirements, grading scales, and standardized tests - and the powerful hidden curriculum, including expectations about gender ${ }^{1} . "$

\footnotetext{
${ }^{1}$ Lindsey, Linda L. Gender roles: a sociological perspective. 5th ed. London: Routledge, 2016. 305.
} 
In this documentary, the director aimed to disseminate and celebrate the brave work of two female educators, who designed and are currently engaged in the execution of this program within the framework of public education. Likewise, the documentary encourages and recognizes the efforts of both parents and children who with open minds have embraced the alternative education offered by TGCS. It highlights the instinctive responses children gave to the interviewer, while informing the audience on the candid yet profound acceptance and understanding they hold about the multifaceted expressions of gender and identity. Sadly, we still hear of countless cases of bullying and of the most virulent hate crimes in Canada and around the globe, targeting individuals who do not conform to binary gender stereotypes.

In the following chapters of this paper, I will: discuss the rationale adopted in producing a film on the subject of children's gender identity and the educational system; briefly look into the social and political aspects justifying a program like the one held by this school, which offers a safe space for gender-alternative children and teens in Toronto; expound the methodology I used in the production of the documentary; and, finally, deliberate on the relevance of my film within contemporary culture. 


\section{Chapter One}

Project Rationale 


\section{Gender-based Violence}

\subsection{VAWG}

Violence against women and girls persists and is a global pandemic. It affects an exceptionally high proportion of the population around the world. In the words of Ban Ki-moon, 8th Secretary-General of the United Nations: "Violence against women and girls is a human rights violation, public health pandemic and serious obstacle to sustainable development. It imposes large-scale costs on families, communities and economies. The world cannot afford to pay this price $^{2} . "$

In the face of pervasive, scandalous, and shameful acts of violence against women, against gender-alternative individuals, and against the environment, new paradigms in education seem crucial to our survival. Almost every institution and system of beliefs in the world endorses the dominator's paradigm, a concept developed by Riane Eisler, which invites us to ponder on "the struggle [of] those who cling to patterns of domination and those working for a more equitable partnership world ${ }^{3}$.

Physical, sexual, and psychological crimes committed expressly against women for the sole reason that they are women is a manifestation of power inequality between genders. Generally understood, the hateful and avoidable killing of women by men, for the sole reason they are females, is termed femicide ${ }^{4}$.

\footnotetext{
2 "Violence against women, sexual violence, women, abuse, discrimination, Elimination of Violence against Women." United Nations. Accessed June 29, 2017. http://www.un.org/en/events/endviolenceday/.

3 Eisler, Riane Tennenhaus. Sacred Pleasure: Sex, Myth, and the Politics of the Body. (San Francisco, CA: HarperSan Francisco, 1995), 191.

4 "Understanding and Addressing Violence Against Women." 2012. Accessed July 03, 2017. http://apps.who.int/iris/bitstream/10665/77421/1/WHO_RHR_12.38_eng.pdf.
} 


\subsection{Hate Crimes Against the LGBT Community in Canada}

Hate crimes against non-binary-conforming individuals are the most violent in Canada, according to a 2012 police report ${ }^{5}$. These have increased in recent years and are the most brutal, according to Statistics Canada, compared to other types of hate crimes (racial or religious), which have been diminishing ${ }^{6}$. These crimes, unfortunately, are mainly carried out by youth between the ages of 12 and 24 and are mostly directed at and committed by males ${ }^{7}$. It is also disheartening to know that even within a frame of legal equality, one 1 of every 4 homeless youth in Toronto identifies as $\mathrm{LGBT}^{8}$. These unacceptable situations target alternative sexual identities, which call for a more dedicated and inclusive, pan-Canadian approach coming from the educational system.

Lesbian, gay, bisexual, and transgender rights in Canada have consistently gained recognition and legal space since the 1960s, and Canada is considered one of the global leaders in this area. Nevertheless, discrimination persists in several places, especially within the school system 9 , as shown by the following data from recent studies, published in 2015 by Rainbow Health Ontario ${ }^{10}$, and supported by academic research:

\footnotetext{
5 "Police-reported hate crime in Canada, 2012." Government of Canada, Statistics Canada. November 30, 2015. Accessed June 18, 2017.

${ }^{6}$ Cohen, Tobi. "Hate Crimes against Gays Doubled in Canada." Canwest News Service. Accessed October 22, 2016. http://www.canada.com/life/Hate crimes against gays doubled Canada/3155968/story.html.

7 Takeuchi, Craig. "Hate Crimes in Canada: Most Violent against Gays, Black People Most Targeted Racial Group." Straight Talk. June 27, 2014. Accessed October 25, 2016. http://www.straight.com/news/675221/hate-crimes-canada-most-violent-against-gaysblack-people-most-targeted-racial-group.

8 Abramovich, Ilona Alex (2012). "No Safe Place to Go LGBT - Youth Homelessness in Canada: Reviewing the Literature." Canadian Journal of Family and Youth, University of Alberta, 4(1). 29-51

9 Krishna, Rau. "Lesbian, Gay, Bisexual and Transgender Rights in Canada." The Canadian Encyclopedia. June 16, 2014. Accessed October 28, 2016. http://www.encyclopediecanadienne.ca/en/article/lesbian-gay-bisexual-and-transgender-rights-in-canada/.

10 Rainbow Health Ontario. RHO Fact Sheet: LGBTQ Youth Suicide, 2015. Accessed October 19. doi:10.1075/ps.5.3.02chi.audio.2f.
} 


\subsubsection{LGBT Youth}

- 4 out of 10 youth from the LGBT communities in Canada, the US, and New Zealand, have considered suicide. 1 out of 3 have attempted it ${ }^{11}$. In an Ontario study involving 139 youth, more than half of them had considered suicide. A majority of males had considered such an attempt because of their sexual orientation $^{12}$.

- Those who faced family rejection were over 8 times more likely to attempt suicide and 6 times more likely to suffer from depression ${ }^{13}$.

\subsubsection{Trans Youth}

- In Ontario, a study found that $47 \%$ of trans youth age 16-24 had contemplated suicide, while $19 \%$ of them had made an actual attempt ${ }^{14}$.

\subsubsection{Aboriginal LGBT and Two Spirited Youth}

- Aboriginal people have a suicide rate 800 times higher than the national average. Two-spirited individuals (a term distinguishing aboriginal sexuality and gender alternates from those of colonial society) who come out are at risk of violence, rejection, and expulsion from their communities ${ }^{15}$.

- First Nations individuals are subject to multiple intersecting oppressions. This adds to cumulative traumatic experiences, which may not only over-tax their resilience but also increase health disparities. Suicide attempts and completion of suicide in relation to the First Nations gay communities are staggering; some of the groups that have been studied reported: $47.3 \%$ of gay youth considered suicide, in comparison to $23.6 \%$ of their straight peers, and $23.2 \%$ had attempted it, compared to $11.1 \%$ of their straight peers ${ }^{16}$.

\footnotetext{
11 D'Augelli, A. R., Hershberger, S. L., \& Pilkington, N. W. (2001). Suicidality patterns and sexual orientation-related factors among lesbian, gay, and bisexual youths. Suicide and Life-Threatening Behavior 31 (3), 250-265.

12

Mattson, S. R. (2012). Growing up gay or bisexual: The experiences of young gay and bisexual men in Windsor and Essex County, Ontario. (Unpublished Ph.D. dissertation). Windsor, ON: University of Windsor.

13 D'Augelli, A. R., Hershberger, S. L., \& Pilkington, N. W. (2001). Suicidality patterns and sexual orientation-related factors among lesbian, gay, and bisexual youths. Suicide and Life-Threatening Behavior 31 (3), 250-265.

14 Bauer, G., Boyce, M., Coleman, T., Kaay, M., Scanlon, K., \& Travers, R. (2010). Who are trans people in Ontario? 1 (1) Toronto: Trans PULSE E-Bulletin. http://www.ohtn.on.ca/Documents/Publications /didyouknow/july28_10/E-Bulletin.pdf

15 Chandler, M. J., \& Lalonde, C. (1998). Cultural continuity as a hedge against suicide in Canada's first nations. Transcultural Psychiatry, 35, 191-219.

16

Barney, D. D. (2003). Health risk-factors for gay American Indian and Alaska Native adolescent males. Journal of Homosexuality 46 (1), 137-157.
} 


\subsubsection{Violence and Harassment}

- A large study in Canada found that $70 \%$ of students have heard the expression "that's so gay," at school every day, and 48\% also heard homophobic slurs on a daily basis ${ }^{17}$.

- The LGBT community reported they were subjected to general harassment varying from $57-92 \%{ }^{18}$.

- 1 in 5 trans Ontarians reported having been physically or sexually assaulted, while 1 out of 3 experienced verbal harassment or threats because of their trans status ${ }^{19}$.

- Those who are survivors of transphobic violence are at higher risk of suicide. Over $51 \%$ of those who were subjected to bullying, physical assault, harassment or expulsion from school due to their trans status attempted suicide. Such attempts rose to $59 \%$ if they were harassed or bullied by their teachers. If their teachers sexually assaulted them, this figure increased to $69 \%$, and if their teachers physically assaulted them, it went up to $76 \%{ }^{20}$.

The statistics above reflect only a part of the results published by Rainbow Health Canada and by the Statistics Canada website. The compilation of data stresses a number of factors impacting LGBT youth, such as sexual identity, gender expression, parental acceptance, discrimination, and victimization, playing a key role in the risk of suicide. Other intersecting aspects such as class, race, and religious beliefs can either enhance or attenuate self-destructive tendencies. What we can infer from these statistics is that homophobia and transphobia at schools and within the educational system have appalling consequences for students who self-inflect harm. It also tells us that the consequences for

\footnotetext{
17 Taylor, C., \& Peter, T. (2011). Every class in every school: Final report on the first national climate survey on homophobia, biphobia, and transphobia in canadian schools. Toronto, ON: Egale Canadian Human Rights Trust. http://archive.egale.ca/EgaleFinalReport-web.pdf

18 Cowan, G., Heiple, B., Marquez, C., Khatchadourian, D., \& McNevin, M. (2005). Heterosexuals' attitudes toward hate crimes and hate speech against gays and lesbians: Old fashioned and modern heterosexism. Journal of Homosexuality, 49 (2), 67-82.

19 Bauer, G., Boyce, M., Coleman, T., Kaay, M., Scanlon, K., \& Travers, R. (2010). Who are trans people in Ontario? 1 (1) Toronto: Trans PULSE E-Bulletin. http://www.ohtn.on.ca/Documents/Publications /didyouknow/july28_10/E-Bulletin.pdf

${ }^{20}$ Nuttbrock, L., Hwahng, S., Bockting, W., Rosenblum, A., Mason, M., Macri, M., \& Becker, J. (2010). Psychiatric impact of gender-related abuse across the life course of male-to-female transgender persons. Journal of Sex Research 47 (1), $12-23$.
} 
society later on are also devastating, since young bullying individuals who have not been sensitized to gender realities most likely will not change their behaviour or views.

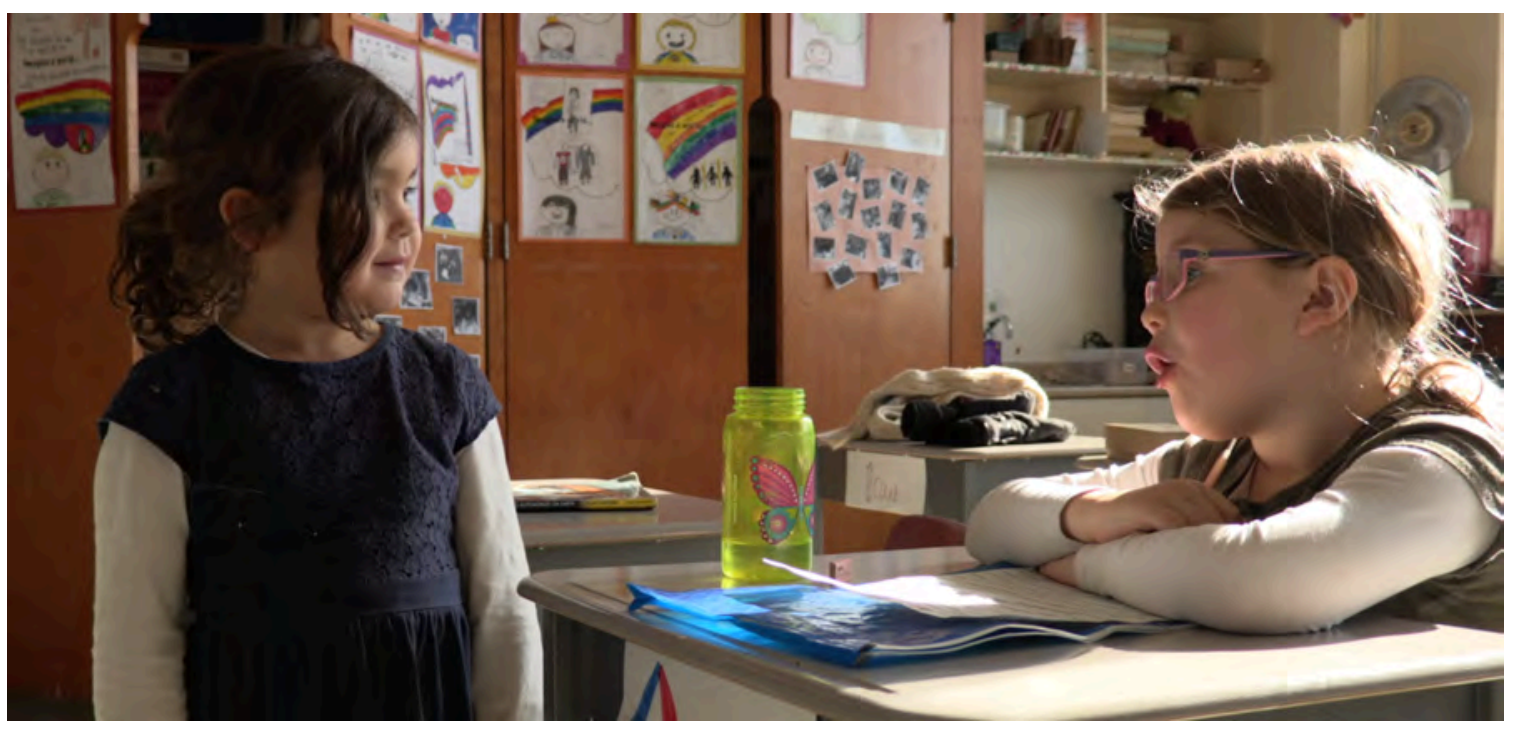

Figure 2. Lulu and Mia representing a scene on gender-based bullying at TGCS (2017) 


\section{Chapter Two}

Project Background 


\subsection{On Gender}

Since the 1950s, the word "gender" has taken on a more ample meaning to distinguish the self-assigned or performing sexual social role (personal identity), from biological sex. Gender role, then, speaks to "all those things that a person says or does to disclose himself or herself as having the status of boy or man, girl or woman, respectively ${ }^{21}$." These roles in an individual can be read from clothing, speech patterns, movement, and many other expressions, which are also influenced by culture. During the past few years, social media has increased the popularity of this term, disseminating images and stories that instil a perception of equality within gender expressions and identity.

The gender binary of male and female has been adopted by many societies, although others recognize a third gender, such as the Two-Spirit by North American nations, the $f a$ 'afafine by Samoans, and the hijras by South Asian groups in India and Pakistan, regarded to be neither male nor female. Additional categories could also include multiple templates of behaviour independent from male or female gender roles, and also, a state of sexlessness.

\subsection{Feminism and Gender}

In broad terms, feminism has diverse approaches to gender, out of which three are the most commonly accepted. The first one acknowledges gender roles as behavioural norms associated with males and females within the social milieu in which they happen. Roles resulting from the biological differences occurring between the sexes are accepted as natural. This camp is comfortable with the idea that women are legitimate offspring

\footnotetext{
21 Money, J. "Psychologic Approach to Psychosexual Misidentity with Elective Mutism: Sex Reassignment in Two Cases of Hyperadrenocortical Hermaphroditism." Clinical Pediatrics 7, no. 6 (1968): 331-39. Accessed October 18, 2016. doi:10.1177/000992286800700608.
} 
caretakers, by reason of the biological function associated with bearing children and breast-feeding them, within a just system. The second approach agrees that biological sexes may have diverse natural strengths; nevertheless, battles exist for equality between both genders, instead of valuing the roles traditionally assigned to men. The third approach contends for the abolition of the concept of gender, since, they say, no one can perform the ultimate standards of any of the sexes; and further, creating ideals of gender is unhealthy, for it is impossible for anyone to meet them ${ }^{22}$.

Pondering these concepts as well as the dynamics arising out of how humans identify sexually, we come to understand that " $[\mathrm{g}]$ ender is a key dimension of personal life, social relations and culture." That "[i]t is an arena in which we face hard practical issues about justice, identity, and even survival ${ }^{23}$." Moreover, the world is undergoing a critical period on gender issues, and a gender revolution, while at the same time, right-wing views in Western countries seem to be making a comeback, threatening the gains made by the feminist movement and LGBT groups during the last few decades.

\subsection{Why Gender?}

Gender inequalities have always accosted and bewildered me. I was born into a dysfunctional family, which was presided over by a father who was a lawyer: a good man in many respects, but violent, who victimized my mother; since early in my life I was battling against gender disparities. I still remember at the age of five, when I saw my father treating my mother unjustly, coming to her defence and being slapped in the face by him. In that moment, I declared him my sworn enemy. The gender regime playing out in my family during my upbringing was not only dictated by the neo-colonial patriarchal

\footnotetext{
22 "Feminism and Gender." New World Encyclopedia. Accessed October 18, 2016. http://www.newworldencyclopedia.org/entry/Gender.

23 Connell, Raewyn. Gender in World Perspective. Cambridge: Polity, 2009. Kindle.
} 
morals operating in the $60 \mathrm{~s}$ and $70 \mathrm{~s}$, but by the social expectations and economic pressures of middle-class families, like mine, composed of three sisters, three brothers, and myself, the youngest, in the heart of Colombia. My mother was a well-read, refined naïve style painter who did not attend university, brought up in a more or less wealthy family. My father was the son of a renowned politician coming from a small ultraconservative province, educated as a lawyer in Bogota, the capital city, where he met my mother.

I may not have taken the most sensible decision at the age of five in becoming a staunch adversary of my father and a champion of justice in the protection of my mother, which naturally, threw me into rough pre-teen and teen years. I stubbornly fought to make things right until I left home at the age of 27 to seek spiritual guidance in India, marked by psychological and emotional scars.

These deep-rooted personal concerns on gender issues echo the social dynamics currently surfacing with unprecedented acceleration. They include "questions about human rights, global economic injustice, [post-truth politics], environmental change, relations between generations, violence, both military and personal, and the conditions for living well ${ }^{24}$." To make this personal story short, I will briefly expose some of the biographical circumstances that fine-tuned me as an activist, working in any media I could, raising awareness on social and cultural taboos.

The following lived experiences have shaped me as a passionate, relentless advocate for social and ecological issues on which there is a veil, taboo, or stigma: the murder of a sister at the hands of her lover in Colombia, while I was in Australia in 1988; the suicide

24 Ibid. 
of a brother in 1991, after my return to Bogota, at the end of a three and a half year soulseeking tour I had made across Eastern countries, Australia, and Europe; sexual abuse at the hands of my sister's husband when I was 17; my ex-wife asking me for a divorce barely after a month of our arrival to Canada in 2003, a process in which I had served as primary applicant; the alienation of values of my daughter by the media and by the break of my marriage and divorce combined with a difficult immigration process; the seizing of leadership of my family by my then newly rich ex-mother-in-law, amid the separation; my daughter having come at risk of being enlisted by a prostitution ring at the age of 12 in Canada; my elder sister taking over my mother's assets and preventing her from seeing the rest of her family; my own cutting off from most of my family after I made these issues public; and, finally, the recent revelation of sexual abuse cases that occurred at the Bihar School of Yoga ashram in India, a place where I lived for a year. As a result of these daunting events, I have come to understand that the dominator's paradigm has been universally internalized, entrenched in both men and women, as a systemic post-colonial, social, cultural, and economic dynamic, capable of destroying any ethics of care.

Feminist, ethicist, and psychologist Carol Gilligan explains the ethics of care theory as follows:

My research on identity and moral development led me to identify the ethics of care as a "different voice" - a voice that joined self with relationship and reason with emotion. By transcending these binaries it shifted the paradigm of psychological and moral theory. The ethics of care starts from the premise that as humans we are inherently relational, responsive beings and the human condition is one of connectedness or interdependence ${ }^{25}$.

25 Gilligan, Carol. "Ethics of Care." 2015. Accessed November 29, 2016. http://ethicsofcare.org/carol-gilligan/. 
Up to the present, we know of no society that consistently ranks the status of female higher than that of male ${ }^{26}$; therefore, it is urgent to contest the private and institutional regimes of gender in Canada, in which LGBT groups and every other individual not belonging to the male white-race group grades lower or lowest, according to racist ideologies. Although Canada ranks second in the Social Progress Index amongst all nations with regard to tolerance and inclusion ${ }^{27}$, racial inequality and competition for resources amid a society with increasingly smaller majorities and bigger minorities puts a strain on all the country's systems ${ }^{28}$.

\subsection{A Bumpy Road to Gender Splendour}

The following testimonies and memoirs on the trajectory of how my work as a visual artist and documentarian activist has evolved is relevant to the place I stood by the time I engaged the Documentary Media MFA program, and where I stand now, while writing this thesis shortly after having finished the production of the documentary. Future students who access this paper may gain a better understanding of the importance of documentary as a tool to impact and transform the minds of an audience.

While completing a second Bachelor's degree in anthropology (2011) in Montreal, an academic discipline in which I found a space to make some sense of human behaviours, I came up with the idea of making a documentary on the subject of sexual violence against children. The production of this documentary posed serious problems of ethics and representation because of the impossibility of interviewing children who had been

\footnotetext{
26 Lindsey, Linda L., and Sandra Christie. Gender Roles: A Sociological Perspective. (Upper Saddle River, N.J: Prentice Hall, 1997), 2.

27 Gilmore, Scott. "Canada's racism problem? It's even worse than America's." Macleans.ca. March 16, 2017. Accessed July 06, 2017. http://www.macleans.ca/news/canada/out-of-sight-out-of-mind-2/.

28 Abedi, Maham. "Canada is 150 and still needs to face its racism problem: advocates." Global News. June 29, 2017. Accessed July 06, 2017. http://globalnews.ca/news/3556823/racism-in-canada/.
} 
abused. In fact, documenting child sexual abuse either as evidence or as re-enactment (documental or fictional) constitutes a crime in itself. Such images would give rise to exceedingly strong emotions, and most probably, to social and political upheaval. Despite the devastating effects of child sexual abuse, documenting this crime at the moment of its perpetration is unimaginable for most of us. I understand that a child's testimony could cause further trauma to the child ${ }^{29}$. However, I believe that the fact that the law impedes the dissemination of children's own voices making it almost impossible to hear about such experiences from their points of view and sentiments, obeys a patriarchal dictate. A patriarchally based justice system may not seem interested in portraying the systemic problem, nor in indexing males as the primary perpetrators of these hideous crimes ${ }^{30}$. For a couple of years I pondered a way in which it could be done.

Initially, for a course in women's studies at the Simone de Beauvoir Institute at Concordia University, I produced a symbolic work addressing the issue, utilizing photographic assemblages that could call attention to and instigate change on the taboos surrounding this crime. This body of work has never found a gallery willing to show it despite some attempts. This frustrated intention to exhibit the work has elicited in me some incredulity and wonderment on how private and public galleries have become spaces for a bland, not-asking-many-questions type of art. These institutions and businesses do not dare to risk losing corporate, official, or private patronage; certainly, in present times, "[m]ore and more, people do not wish art, criticism, and education to

\footnotetext{
29 Government of Canada, Department of Justice, Research and Statistics Division. "Victims of Crime Research Digest, Issue No. 2, 2009." Government of Canada, Department of Justice, Research and Statistics Division. January 07, 2015. Accessed July 08, 2017. http://www.justice.gc.ca/eng/rp-pr/cj-jp/victim/rd09_2-rr09_2/p3.html.

30 Canada, Government Of Canada Statistics. "Police-reported sexual offences against children and youth in Canada, 2012." Government of Canada, Statistics Canada. November 30, 2015. Accessed July 08, 2017. http://www.statcan.gc.ca/pub/85-002x/2014001/article/14008-eng.htm\#a9.
} 
present reality as problematic ${ }^{31}$." This work, under the name of Gris-gris contre l'abus $(2010)^{32}$, merges anthropological thought, feminist theory, and photography as an artistic/pop culture endeavour, utilizing the concept of an amulet of the African-American hoodoo folk magic tradition.

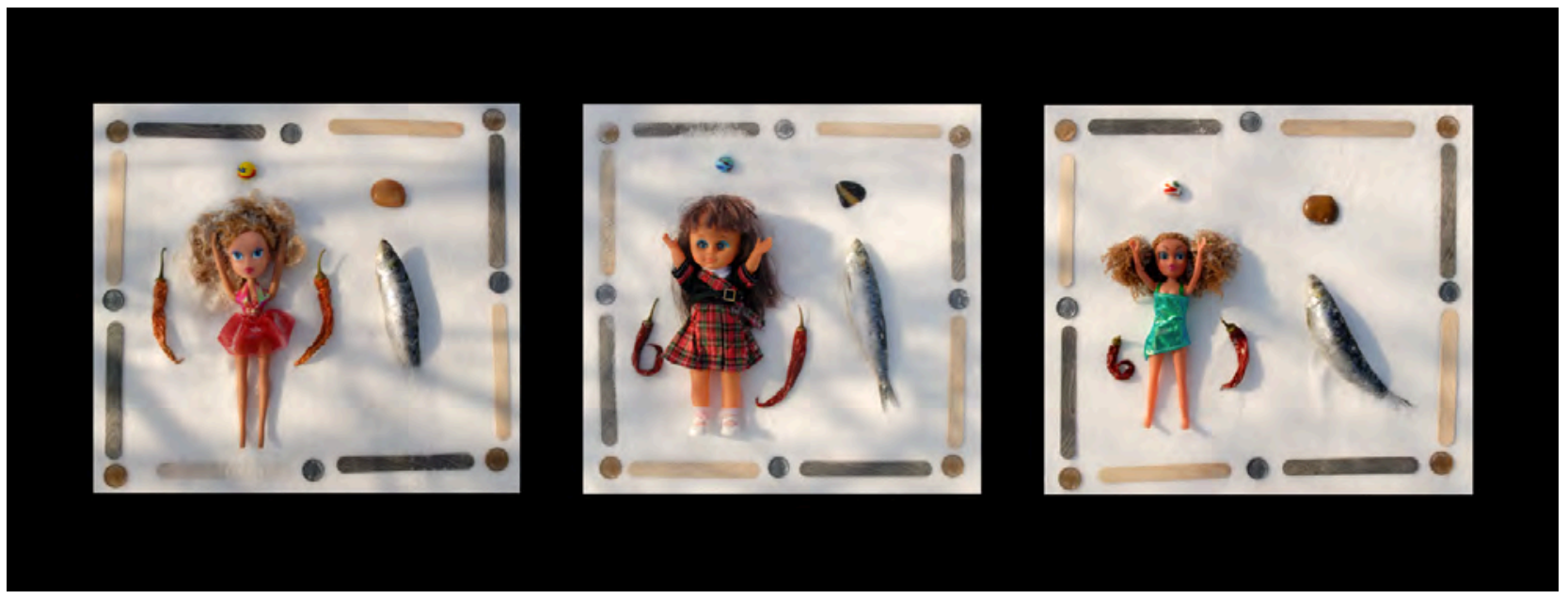

Figure 2. Gris-gris contre l'abus A (2010)

After finishing my studies in anthropology, I moved back to Colombia determined to make such a documentary on the commercial sexual exploitation of children. The argument was that one of the most devastating and extreme ways to destroy the dignity, the physical and psychological wellbeing, and the illusions of an individual was to subject such a person to sexual abuse or to sexual exploitation. Furthermore, if the victim were a minor, the consequences for the child, most likely, would be irreparable. After some months of trying to secure sponsorship, no one seemed interested in the subject or willing to back it. The vulnerability of sexually exploited children versus getting to hear their voices poses an ethical issue, but not hearing them also does.

\footnotetext{
31 Steiner, Wendy. The Scandal of Pleasure: Art in an Age of Fundamentalism (Chicago: University of Chicago Press, 1995), 3.

32 Gómez, Camilo. "Gris-gris Contre L'abus." CAMILO GOMEZ-DURAN - PHOTOGRAPHE - FOTOGRAFO - PHOTOGRAPER. 2010. Accessed November 14, 2016. http://www.camilogomezduran.com/p_gri.html.
} 
Once I enrolled in the Documentary Media program, during my first year of studies, I realized that trying to interview children for a documentary on the subject of sexual abuse and exploitation in Canada would have taken me at least a year or two, a possible conundrum of legal, consent, and institutional hoops. Additionally, such endeavours, undertaken by an immigrant who had not produced a documentary before, without any connections nor symbolic and economic capital, could have prolonged the process. These conditions would have put me at risk of being unable to complete the required documentary in partial fulfilment of the thesis work. This project was the first I abandoned during the program.

I kept myself focused on the field of gender and violence against women, and soon moved into the question of the construction of masculinities within the educational system. After a good deal of research, I refined the concept and presented it as the Master's Research Project (MRP) for the program at the end of my first year of studies. The research question was: "Should boys, girls, and transitioning children be coached into adulthood in a way that teaches them to more thoroughly embrace, admire, and celebrate the feminine?"

As I was starting some interviews, a colleague from the program called my attention to a recently released documentary addressing the issues on the construction of masculinities in North America, called The Mask You Live In (2015) ${ }^{33}$. I found this documentary to comprehensively depict the kind of interviews I had envisioned. This was my second abandoned project, as I thought that the novelty of the subject with which I intended to work was no longer there.

33 The Mask You Live In. Directed by Jennifer Siebel. Performed by Carolyn Heldman. The Mask You Live In. Accessed December 2015. http://therepresentationproject.org/film/the-mask-you-live-in/. 
Again, for the production course proposal, just before the summer period in which students are supposed to start the filming phase of their MRP, I had no plan except for a narrative of the failed projects up till then. But I was still determined to work on the gender topic. One of my teachers came to the rescue and told me about the GS week, a series of workshops taking place at the school her daughter had attended. She put me in contact with one of the teachers running it. What followed was a long process of Ryerson, Toronto District School Board (TDSB), TGCS research ethics boards, institutional and parents' committees, and staff councils' examination of the proposal and approvals. This process took more than nine months, time which I dedicated to producing other pieces, reading extensively on film production, and learning film-editing software. 


\section{Chapter Three}

\section{Methods}




\subsection{Conception}

It is important to integrate a more determined pedagogical approach into the educational system that mentors children into the validation of human rights, such as gender equality, social justice, and environmental responsibility. These values are inspired by ethics of care. This is the idea sustaining the documentary I was committed to produce, while disseminating a most progressive and radical practice of the educational system in Toronto.

As I envisioned it, explicitly and under the surface of my project, these are its communicational purposes: to advocate for and to support the work of courageous educators advancing such ideals, who have embarked on the task of giving children the tools to accept and celebrate who they are with regard to gender expression and identity; and, to sensitize an audience to the pandemic of violence against women and girls, and mainly, for this project, on that exerted against the LGBT youth community.

It was partly my idea that the narrative patterns given by children themselves would shape the path of the documentary, describing the adventure of achievement concerning gender stereotypes, the celebration of transitioning children at an early age, and the predicaments of violence against the LGBT youth community.

The idea came more into shape while pondering gender equality issues in Canadian schools. Once I got to know this program better, inspired by its amazing practice, I said to myself that GS should be approached and given symbolic recognition. A documentary on GS occurring in the progressive TDSB, specifically, at TGCS, could be used to pressure parents and teachers, and the provincial and federal governments, to create a weeklong program for schools. This would help gender stereotypes to be analyzed and challenged across Canadian schools. By disseminating this raising-awareness and 
diversity celebration to other schools in Canada through a documentary, boys, girls, and transgender individuals would be invited to incorporate the need of defying gender stereotypes through workshops, questioning sports engagement, professional career preferences, bodily appearance expectations, dress codes, and many other social and cultural practices that uphold gendered systems of oppression. Also, children would more widely be encouraged to critically assess sexist literature and media, while analyzing and deconstructing them according to gender stereotypes. Along with learning activities and social interactions in the pedagogical space, children of all backgrounds and ages would have the opportunity to evaluate the gender binary concept on which most societies around the world base the modelling of personhood. This would enable transitioning and non-transitioning children to be more at peace with their own gender expressions and identity, and more accepting and respectful of that of others.

I had an ambitious plan for the documentary of asking children to use their phones to record interviews with their peers, previously having obtained parents' consent. I also envisioned a plot in which a teen girl would be the protagonist, who writes a letter to the TDSB, to the Premier of Ontario and to the Prime Minister of Canada, to name and designate a day of awareness, new learning, reverse ritual activities, and celebration of the subject of gender equality.

\subsection{Development}

I should have known that putting in the same paragraph the words children, sexuality, and video was asking for trouble, even if coming from a standpoint of scholarship. I would also have been grateful if advised beforehand that this research topic proposal, coming from a mature Latino male would raise bigger suspicions than if coming from a white local individual. The invisibility and contrivance of white supremacy was subtly or 
overtly evident as an "ongoing institutional white control while reinforcing the ideolog[y] of $[\ldots]$ meritocracy ${ }^{34}$." Partially unaware of such a societal contraption, with the determination and the innocence of the activist mind, I started the process by submitting my project to the ethics protocol online review system of the Ryerson Research Ethics Board (REB).

The first hurdle a student from our program will find with this format is that if not formulating a model of research based on questions that will render statistical results, then, the documentary endeavour falls into a deep grey area where audio-visual documentary production is at odds with the protocol. This happens because documentary in a broad sense is not trying to extract evidence-based, verifiable social trends from interviewees based on data analysis, but instead is founded on subjective information and views that can invite an audience to make sense of any aspects of societal or cultural phenomena, on which the documentalist wants to focus its work.

Finally, after waiting long, and asking for a meeting with one of the REB committee members, I was cleared on the grounds that my proposal would not make interviewees the subjects of a data analysis research project. This was the core segment of their response:

Based on the information provided it has been determined that the project does not require ethics review or approval. Part of your project will involve interviewing individuals who are not themselves the focus of the research. Additionally, as there is no research question and no analysis of the data to explore the research question then the project does not require REB review. Finally, as you are creating a documentary film it is understood that you will adhere to the principles for ethical journalism.

\footnotetext{
34 DiAngelo, Robin. "No, I Won't Stop Saying." YES! Magazine. June 30, 2017. Accessed July 02, 2017. http://www.yesmagazine.org/people-power/no-i-wont-stop-saying-white-supremacy-20170630.
} 
With this document, additional ones were required, a police check and a premises insurance, the latter of which the TDSB Research Ethics Board and Communications Officer committee also requested. Afterwards, I was able to approach TGCS in September 2016, three months in delay, since it was summer vacation. The teacher from the school to whom I was introduced in early June, communicated to me that she would only be available again until late August. For three months I was not able to produce any footage directly related to my MRP. Nevertheless, I started to gather symbolic images that could be used as cutaways and read on production for documentary film.

I knew, because of the nature of my topic, that at any time I could hit a wall. This is why I also started to work on a short documentary related to immigrants in Canada, as a back-up project, but my thesis was fully being researched and written on the subject of gender.

No longer requiring ethics review or approval for my project on children, gender, and the educational system, I went ahead and tailored a consent form that had some of the points that the REB had asked for. I found that they where pertinent regarding the fact that I would be interviewing a vulnerable group. After revisions with the school committee, the consent form was finally sent to parents in November 2016.

Many parents had agreed for their children to participate in the documentary. But another hurdle was raised by one of the members of the parent's committee, and I was summoned to the school to discuss the consent form in January 2017. This person demanded I make changes to the consent form as if I would be conducting scientificbased research. This individual evoked the fact that a close relative was on the Research Ethics Canada board. There was an unsettling demeanour coming from this individual, 
with whom I chose not to engage, since for me, the project of highlighting the bullying that transitioning children undergo in the educational system was far more important than to argue with this individual. Unfortunately, this individual asked the schoolteachers to return the already acquired consent forms to the parents, casting a shadow of doubt on the project.

One of the main points to be clarified had to do with parents being able to withdraw consent at any moment before the stage of picture-locking the documentary, which I had already agreed to. Another point had to do with the fact that if there were to be interest from the media for public broadcast, I would have to ask for extra approval from parents. The other one had to do with the protection and destruction of the gathered material after 10 years.

I was determined to go ahead with the project and since timing was starting to be even more critical, I decided not to risk another consent form refusal. I took the case and consent form to the Ryerson Legal Counsel Office of the General Counsel and Secretary of the Board of Governors, again to the Ryerson Research Ethics Board, and again to the TDSB Research Ethics Board and the Media Relations Committee. This process took more than a month. Strangely, one of the individuals who had my case at the Legal Counsel Office was not answering my emails and taking too long to revise the consent form. I decided to visit her and see what was going on. When I got to talk to this person, it was not clear to me if she wanted to help me get through or wanted to veto the project. I asked her that very question. After this exchange, she sent the request to the Ryerson REB, again, with recommendations. The REB, in turn, sent it to the TDSB REB and the 
Communications Officer Committee, and other bodies, for a second round of deliberations.

This was the REB answer, which compiled the assessments done in conjunction with different groups at the TDSB:

The Research Ethics Board has determined that your protocol does not require its review.

As Article 2.6 of the TCPS outlines, "creative practice activities, in and of themselves, do not require REB review. However, research that employs creative practice to obtain responses from participants that will be analyzed to answer a research question is subject to REB review." As noted you are engaging in a creative practice - the making of a documentary film - but are not aiming to obtain responses to answer a particular research question. Rather you are aiming to describe an event that takes place as part of a unique community.

After a number of discussions with both the research ethics body of the Toronto District School Board (TDSB) and the Communications Office of the TDSB, it is clear that they agree with the Ryerson REB decision that this project is not "research" and is not subject to their oversight. Both offices, however, made suggestions about how the consent and voluntariness of potential participants of all ages can be managed. These recommendations have been both discussed with you and incorporated into your revised consent form. You have also noted that you will be working with the Principal and teachers at the school, as well as the Parent Council, to ensure that ethical standards are maintained, in terms of voluntariness, informed consent and assent where appropriate.

Finally, I was able to get the school to send out the new consent form, a couple of weeks before March Break. At this point, I was already delayed ten months in gathering the necessary footage, compared to the other program members of my cohort. Unfortunately, fewer parents agreed than before, but the result was that a score of children would be participating in the documentary.

After months of stress, but with courage and determination, inspiration I took from documentary production books and from a thesis almost fully written around the subject of GS, I was cleared to have access to parents and children in late March 2017. GS week took place during the first week of April, the period in which I gathered most of the 
interviews that were used for the editing of the documentary. Still, I could perceive some resistance from certain individuals at the school, who, apparently, were not friendly with the idea of having someone recording on their premises and about their activities.

A documentary on societal problems on which there is a veil, taboo, or stigma attached to them takes on a life of its own, establishing a problematic conversation, first with its participants, then, with the audience.

\subsection{Project Realization}

All the cutaway footage I had gathered before starting interviews was added to the lot of recordings produced later during GS week. The challenge then was to revise all the material, classify it, and group it in the best way possible, so as to be able to edit and construct the narrative arc, in the smoothest way possible taking into consideration that time was very short; I had only a couple of months left. It took me almost three weeks of intensive work to go through such a process.

Fortunately I had gathered good quality nature related cutaway material beforehand, and also, had recruited a couple of friends who generously helped me learn the editing program more in depth and develop the animated graphics. Before GS week, I was able to get in touch with the brother of one of the parent interviewees, who then came to the school to teach children a song he had composed for his pupils at a school in New York, and that perfectly expressed the ideals of inclusion within the educational system. He was also very generous by letting me use the song as a background for the epilogue of the documentary.

The initial idea of having a pre-teen or an early teen girl or boy to enact the writing of a letter to Canadian politicians, was not feasible because cooperation from the school 
teachers was limited, due to the time constraints we had faced and other professional commitments they had acquired beforehand.

I was practically filming by myself, with the exception of some hours when I had help from some of my colleagues. Otherwise, due to the intensity of work to be done during a short lapse of time, I was handling a 4K Cannon XC10 camera with an independent Zoom H5 audio recorder on my own. In order to be able to develop the plot I had in mind, I would have required more days at the school, which were also denied to me on grounds of not disturbing the natural flow of the classes and workshops. During certain moments, I could feel the atmosphere charged by internal tensions around the idea of making the lives of children public. I had to navigate all these complexities to the best of my abilities, in order to get the interviewees in the school to open up and give me significant responses. In summary, I had very successful interviews with teachers, the school principal, parents, and children, despite time constraints, resistance, and limited collaboration from school personnel, especially during GS week.

The narrative arc that I built came together organically around two basic concepts: the GS week workshops and the notion of bullying. I understood that what is crucial for a transitioning child is to be safe at school from transphobic harassment. Having this in mind, I conducted the interviews and edited them so as to cause a major impact on the audience regarding how difficult it can be for a child to deal with the fact that they are not comfortable with the biological sex they have been assigned at birth.

I edited the footage building the structure of the documentary, as advised by my supervisor, in trying to give children the most screen time. I decided not to juxtapose cutaways over the children's responses and body language, since their unfiltered 
responses and demeanour were so engaging, while putting more of the weight of the cutaways onto the adult interviewees.

Guitar music for the intertitles came at the very last minute, by a neighbour who generously played for my sound recording device.

The added layer of children's poetry came from a book I wrote to my daughter when she was five, self-published in Spanish and entitled, "Lullabies, Short Stories, and Verses." 


\section{Chapter Four}

\section{Documentary Relevance}




\subsection{Influential Films and Documentaries}

There are two films that are stuck in my memory with permanent glue. I do not have to scout my brain and body to bring some of their scenes and sentiments into vision and reanalysis. These are not documentaries, but they do inform my activist photography practice and the way I conceive documentary. One of the films is part of a series of independent short films of minimalist style, synthetizing the absurdity, alienation, and pessimism of human existence, while still imbued with refined, intelligent humour. The other film constantly links in my mind with other genres. It is related to the epic wisdom, altruism, and spiritual heights that humans can attain; also, to the realization of how far Homo sapiens can go in the lust for power.

In the first one, starring Roberto Benigni, Bill Murray, Tom Waits, Steven Wright, and others mostly playing themselves in Coffee and Cigarettes (2003) ${ }^{35}$, Jim Jarmusch directs his characters in discussing trivial, absurd, and scientific topics. The underlying existential subject becomes evident once one starts to grasp what lies behind the humour of the eleven different segments, all shot in black and white: obsession, joy, addiction, delirium, racism, miscommunication, strangeness, disorientation and confusion; these illuminate the contradictions of human actions while in search of life's meanings.

From this series, the vignette that struck me the most, "Strange to Meet You" (filmed in 1986$)^{36}$, in which Steven Wright and Roberto Benigni engage in a nonsensical conversation, invites us to read under the layers of the rapport between them, to perceive hidden aspects related to North American social tensions. Such misunderstandings result

\footnotetext{
35 Coffee and Cigarettes. "Strange to Meet You." Directed by Jim Jarmusch. Performed by Roberto Benigni and Steven Wright. 2003. Accessed November 12, 2016. https://www.youtube.com/watch?v=ggqrEMtA3TU.

36 Ibid.
} 
from the use of verbal and body language as a conduit for meaning, eliciting multiple interpretations of what the actors intend to convey.

The other film is a version of The Mahabharata $(1990)^{37}$, which became crucial to my own understanding of the world and of how visual and dramatic arts can impact the audience. It was first staged as a theatrical piece of nine hours in 1985, and then it was edited into a six-hour video and a three-hour movie. This millenary wisdom of the Hindu epic story of the human race, reinterpreted by theatre director Peter Brook, brims with insightful dialogue and events, magnificently performed by actors of numerous ethnicities, which results in a classic that leaves the viewer transformed. Cast, aesthetics, and depth make this film a bijou. My opinion of what makes a good film or not was thoroughly modified by it.

From the documentary genre, I will refer to one that taught me the power this medium has to redirect lives. We had recently moved to Canada and I was battling the new consumerist influences that my daughter was being subjected to. As a yoga teacher and a parent aware of healthy eating, I knew that sooner or later, I would somehow be frustrated by the eating habits she was starting to develop in her adoptive country at the age of ten. Luckily, during that period, Super Size Me $(2004)^{38}$, produced and directed by Morgan Spurlock, was released. The impact it had on her was profound; she became much more conscious of what she eats.

\footnotetext{
37 The Mahabharata. Directed by Peter Brook. 1989. Accessed October 15, 2016. https://www.youtube.com/watch?v=EENh1hxkD6E.

38 Super Size Me. Directed by Morgan Spurlock. 2004.
} 


\subsection{Documentary Ethical Issues}

An activist mind is constantly deliberating over world dynamics. In permanent disillusionment with how actual affairs impact our own lives and those of people we know, with how we are informed by the media, by social dynamics in general, and by politicians' actions in particular, the activist blood steadily simmers. We want to change the world; we need to change the world. We are committed to try and bring awareness in everything we do. We are critical of ourselves and vocal about injustice. We question every building block of culture. We look deeply into its crevices and shout within.

As a father of a 23 year old, I came to the graduate program with a very clear intention of making a documentary that would address any of these social dilemmas. Violence against women and girls is crucial to me. With the help of a generous friend, I started a one-person foundation in Colombia, which I still direct and run remotely. Under its umbrella, I produced some bodies of work related to how patriarchy justifies aggression against females. My interests always revolve around the core factors that I believe are responsible for generating beliefs and behaviours that are destructive to society and to the environment. While in this practice, I try to be most careful about ethical choices around the representation of others, the insider/outsider dichotomy, consent, and power dynamics.

One of the first works closely linked to such ethical issues, which was carried out with the support of the Foundation, had to do with popular memory and social history. Femicide was already starting to be a perceived issue in Colombia in 2012 when I imagined and conceptualized this photo-essay. The aim was to generate visibility, awareness, and debate on the issue of violence against women and transgender individuals in Colombia, which I sensed was urgent to address before it became rampant. 
The participation of women in all spheres of society had increased in recent decades, but they remained marginalized from the most important political and economic positions. It seems that in the patriarchal society we still live in, attributes that "incorporate women's realities of nurture, altruism, cooperative behaviour, negotiation [of] power ${ }^{39}$," and the protection of life, essential aspects of an ethics of care, have become devalued.

Following this train of thinking, I came to believe that violence against women is also linked to the physiological condition of menstruation in a culture that constantly demonizes it, while attempting to fill females with shame and self-hatred ${ }^{40}$. Menses, universally and throughout the ages has been encompassed by a veil, taboo, and stigma. Linking this disfigurement of thought with the fairly recent murder of emblematic Colombian men who were killed for their efforts to extend inclusion and justice, I dashed ahead with a photo-anthropological essay aiming to generate critical thinking with regard to such nonsensical violence and the possible interrelationships it has with femicide. Here is the imagery I produced for this body of work, called Sacred Flow (2013) ${ }^{41}$, which took three months to develop. Formally, it was wrapped up with the help of my friend Sergio Valencia Mejía, an artist and expert in digital retouching techniques.

\footnotetext{
39 Evans, Mary, and Carolyn Williams. Gender: The Key Concepts (Abingdon, Oxon: Routledge, 2013), Kindle edition.

40 Rees, Emma L. E. The Vagina: A Literary and Cultural History. (New York: Bloomsbury Academic, 2013 ), 24.

41

Gómez, Camilo. "Sacred Flow." FUNDACIÓN LINTERNA. 2013. Accessed November 28, 2016. http://www.fundacionlinterna.org/english/proyectos.html.
} 


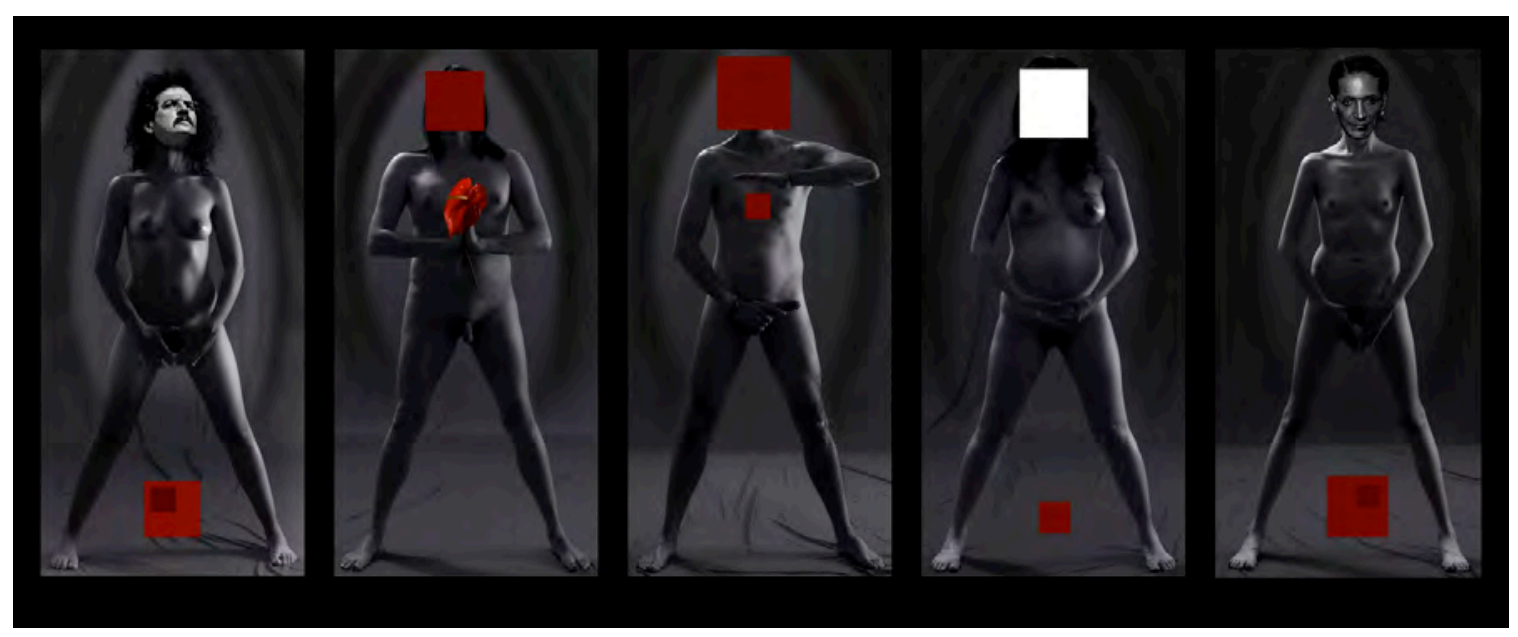

Figure 3. Excerpt of Sacred Flow (2013)

Speaking for others is perceived in some current feminist theories as an "arrogant, vain, unethical, and politically illegitimate [practice] $]^{42}$." This concept is based in the notion that when one speaks for (represents) the other, it is done without the ability to transcend the location from which we are speaking. This is to say that the social and cultural baggage from which one enters the realm of representation inherently carries language that risks authorizing or disauthorizing claims uttered by the original speaker. Oppression and privilege play a salient role in the study of and advocacy for others, bringing into question aspects of power, especially coming from those who are in a hierarchical position speaking for others who are in a disadvantaged or vulnerable space, "increasing or reinforcing the oppression of the group spoken for ${ }^{43}$." This is to say that documentary, paradoxically, can become an instrument that ultimately reinforces preexisting power dynamics.

\footnotetext{
42 Alcoff, Linda Martín. "The Problem of Speaking For Others." The Problem of Speaking For Others | Alcoff.com. 1994. Accessed November 17, 2016. http://alcoff.com/content/speaothers.html.

43 Ibid.
} 
In dealing with the subject of gender, as a cisgender male, I may be the object of criticism, labelling my work as coming from a voyeuristic stance and not from a more subjective, confessional place ${ }^{44}$. In response, I argue that my interest in gender comes from the fact that I am a father of a girl who has been the target of alienating media, and of attacks by men who have sexually assaulted her; from my own experiences transgressing gender roles and stereotypes; from my experience interacting with both men and women; or, from my own claims of being a feminist.

With respect to the photo-essay, Girls and Boys Who Make Boys and Girls (2013) ${ }^{45}$, I will never be able to speak for young women who become pregnant by uninformed/informed choice, by the force of social and cultural mores, or by sexual assault. But I can research the topic, talk to women, and try to interpret their issues, concerns, and feelings while producing a body of work that calls attention to this calamity. Whether I act as an outsider exploiting them, or as an insider who assists in the dissemination of their voice so as to generate awareness and political change, is a question that is always on my mind while working on issues affecting other groups, which ultimately, I come to perceive as also affecting me, even if through indirect pathways.

Did I portray these women with agency or as passive? Did they consent to pose for this project despite the fact that I was a willing-to-pay-a-small-amount male professional photographer? Had I not compensated them economically, would have they consented? These were all concerns that were discussed with the social actors themselves while in

\footnotetext{
44 Middlehurst, Steve. "Context and Narrative." Notes for Assesor. January 17, 2016. Accessed November $23,2016$. https://stevemiddlehurstcontextandnarrative.wordpress.com/.

45 Gómez, Camilo. "Girls and Boys Who Make Boys and Girls." FUNDACIÓN LINTERNA. 2013. Accessed November 28, 2016. http://www.fundacionlinterna.org/english/proyectos.html.
} 
the process of recruiting them. I am inclined to believe that these women would not have consented if the notion of advocacy for a problem affecting 1 out of 5 adolescent females in Colombia were not key to the project ${ }^{46}$.

In this photo anthropological project, I intended to engage the existing social standards and cultural imperatives regarding teenage pregnancy. Its aim was to educate young people while posing a broader question: How do we facilitate adolescents to exercise their rights and freedoms to the fullest? Because of societal norms that prevent the testimonies of minors from becoming a central part of public discourse, we created a mise-en-scène with adult women to address diverse socioeconomic spaces where teenage pregnancy is common. The color photographs were taken from different perspectives and in different public and private spaces, showing an identity in relation to a collective locale, with the intention of bringing viewers as close as possible to the stark realties of teen pregnancy. Figure 4 includes two examples of the above-mentioned body of work, out of twenty images that were produced.

46

46 Daniels, Joe Parkin. "Tackling Teenage Pregnancy in Colombia." The Lancet. April 18, 2015. Vol.385, No.9977, 1495-1496. Accessed July 06, 2017. http://www.thelancet.com/journals/lancet/article/PIIS0140-6736(15)60738-3/fulltext. 

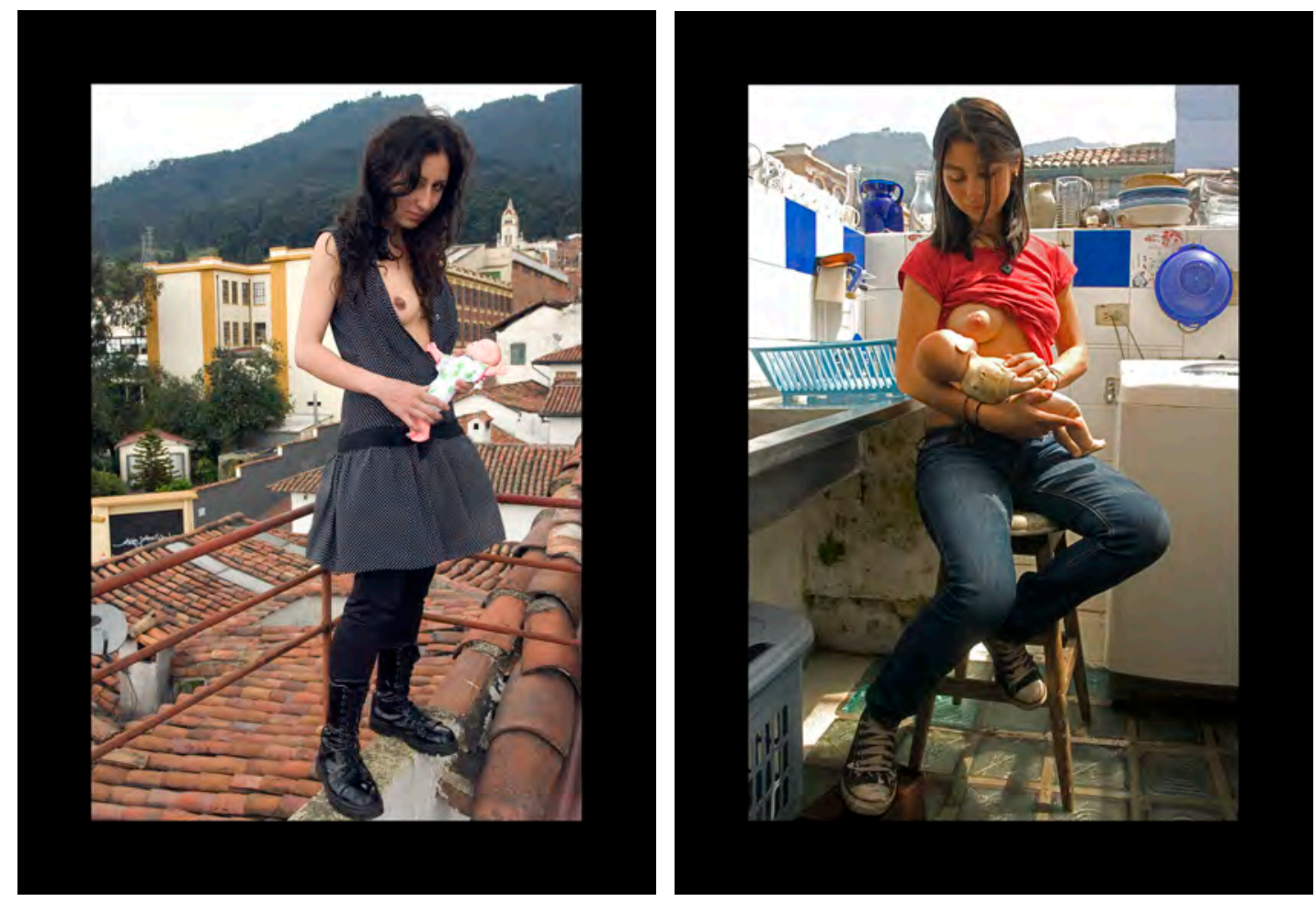

Figure 4. Girls and Boys Who Make Boys and Girls (2013)

These considerations on some of the previous works I have developed are meant to illustrate the learning processes I have had to undergo, and from which some of the readers of this paper may benefit. They compel me to question how I "represent or speak for others without reducing them to stereotypes, pawns, or victims ${ }^{47}$." They help me better understand and tackle the ethical challenges I faced amid the arduous endeavour of coherently expanding a paragraph that links the words "children," "sexuality," and "video." Thus, I felt better prepared to approach a social issue on which there are still veils, violence, and stigma attached, despite living in $21^{\text {st }}$-century Canada, where the rights of women and the LGBT communities are regarded as some of the most advanced and valued.

\footnotetext{
47 Nichols, Bill. Introduction to Documentary (Bloomington, IN: Indiana University Press, 2001), 212.
} 
One of the challenges that I anticipated was how to break the power relations of being a male adult behind a camera while interviewing children, in order not to lead them into responses I could be expecting. To meet this challenge and better sensitize myself, I did considerable reading on gender inequalities in relation to binary and third-sex dynamics. I read articles covering the problem from different angles: lesbian, bisexual, and transgender rights in Canada; hate crimes against children and teens in schools; victimization due to sexual orientation; and, the link between self-esteem and academic achievement within the educational system, many of which have been cited in this paper. I also planned to let the female teachers running the GS week at the school ask the children some of the questions. I wish I could have hidden the camera and extricated myself from the environment in which some of the recordings were made, but that was not possible. Nevertheless, I remained aware of the unforeseen effects that this documentary can have in the lives of those represented, and in the life of the director himself.

\subsection{Concepts Playing Out in the Documentary}

In the research and shaping of the documentary, several concepts came into play informing its theoretical framework, such as activism/advocacy, reflexive ethnography,

performativity, and participative dynamics, on which I will elaborate in the following subsections.

\subsubsection{Activism}

I conceive documentary basically as an educational and an activist practice, even though I understand that not all documentaries address social and political issues 
directly $^{48}$. I asked myself why some of my colleagues shied away from documenting social problems in Canada, such as those that have to do with racism against immigrants, poverty of minorities, housing for youth and adult street dwellers, gender-based violence, wealth concentration, pedophilia, isolation, and many other issues that are in need of being tackled and made more visible. I also wonder why the Documentary Media program at Ryerson University does not establish working connections with NGOs and other organizations to possibly link students to their projects, so the students, if willing, can collaborate, at the same time that they are able to create a professional background enabling the launch or advancement of their careers as socially engaged documentalists.

This also raises the question why universities do not incorporate into every program a series of courses threaded by social activism or by the theoretical and pragmatic layout of societal solutions where students can acquire experience, in addition to working on constructing a more just society, while developing a project that comes to life during the term of their studies.

Moreover, gallery space in universities (and elsewhere) has been sanitized to the extent that art practices really pushing the boundaries to open public conversation on subjects that fundamentally affect social and economic justice are becoming more difficult to find. In present corporate driven North America, the voices of artists are impaired as one of the main ideas' metaphoric articulators of freedom of speech, turning them into unrecognized heroes who ultimately stand up against the consequences of their discourse ${ }^{49}$.

\footnotetext{
48 Ibid, 214.

49 Steiner, Wendy. The Scandal of Pleasure: Art in an Age of Fundamentalism (Chicago: University of Chicago Press, 1995), 36.
} 
Public and commercial galleries could more often open a reserved time and space that facilitates more radical politically engaged art to see the light of day, such as poignant art productions interrelating social and economic oppression, nudity, and sexuality; the latter two topics closely related to the former two. Prudishness in North America in cultural space is alarming, and such a notion silences multi-faceted voices arguing for socioeconomic change. Textilism, the compulsive use of dress, has blinded us from the power dynamics braced-up by nudophobia ${ }^{50}$. Despite the proliferation of information in the Internet, we are witnessing a dark period in history, in which political, economic, and sexual systems of oppression obey a harnessing, disciplinary power commanding all bodily forces to production for the advancement of corporations, the media's cover up of reality, and narcissism ${ }^{51}$.

Corporations increasingly fund all kinds of educational and cultural institutions, and since this has become the trend, the development of knowledge, which should be used to protect the most vulnerable and the environment, has fallen far behind basic notions of pro-social thinking and action. We are now in the coarse hands of neo-conservative forces proposing, "cuts to humanities departments at $[\ldots]$ universities to rebalance funding towards more obviously 'practical' subjects ${ }^{52}$." In addition, students now leave their program with a heavy burden of debt that impacts their mental health ${ }^{53}$, which may

\footnotetext{
50 Just. "Textilism and Nudophobia." January 2008. Accessed July 03, 2017. http://boards1.melodysoft.com/app?ID=addan\&msg=788.

51 Dreyfus, Hubert L. From the Repressive Hypothesis to Bio-Power. In Hubert L. Dreyfus and Paul Rainbow, eds. Michel Foucault: Beyond Structuralism and Hermeneutics (Chicago: University of Chicago Press 1983), 126-142.

52 Tworek, Heidi. "The Real Reason the Humanities Are 'in Crisis'" The Atlantic. December 18, 2013. Accessed November 29, 2016. http://www.theatlantic.com/education/archive/2013/12/the-real-reason-the-humanities-are-in-crisis/282441/.

53 Tencer, Daniel. "Student Debt Is Rising, And Mental Health Problems Are Rising With It." HuffPost Canada. May 30, 2016. Accessed July 03, 2017. http://www.huffingtonpost.ca/2016/05/30/student-debt-mental-health_n_10208520.html.
} 
oblige them to conform to the commands of neo-liberalism - the backbone of corporate culture - making them less socially and economically sensitive to the fate of others.

These modes of social and economic operation that pit us against each other in fierce competition and commodifying relationships with others, with knowledge, and with the environment, have brought our civilization to a social and ecological crux. They are the product of numerous European-centered developments that became anchored in the ideal of reason all through the Age of Enlightenment, bolstered by the resources gathered in Western European colonies and from the system of slavery, all of which gave birth, ultimately, to the Industrial Revolution. Wealth concentration, corporate, social, and ecological irresponsibility, and the economic suffocation of the middle class in neoliberal driven countries, during the time I am writing (June 2017), has emboldened new forms of phallocentric brutality, like the election of Donald Trump as president of the US. Many of the individuals acquiring and maintaining extreme forms of socio-political and economic power, represented by white males or by other patriarchal elite groups around the globe, galvanized within the dominator's paradigm, are historically being called into question. In contrast, the Internet is disseminating a "politics of identity" and a gender affirmation theory, which offer through the voice of documentary and other contesting forms, "pride and integrity [to] marginalized or ostracized groups," while allowing the production of a "memorable form to cultures and histories that [have] remained ignored or supressed beneath the dominant values and beliefs of society ${ }^{54}$."

\subsubsection{Reflexive Ethnography}

In my condition of hybrid-identity, a Latino filmmaker of dual nationality, Colombian and Canadian, and also a professional photographer, an anthropologist, and a filmmaker;

54 Nichols, Bill. Introduction to Documentary (Bloomington, IN: Indiana University Press, 2001), 229. 
in sum, burdened with a personal and academic history, I embarked on the documentation and interpretation of a pedagogical gender critique event happening at a school in my adoptive country. How, from my own subjectivity and detachment, can I try to explain or understand the culture I am immersed in?

It is crucial to incorporate a reflexive approach to comprehend the behaviours, developments, and advancement of societies and cultures, from both personal and broader cultural levels ${ }^{55}$. Through this path, I can gain a wider perspective to grasp how my own biases play a role in the investigation and explanation of a subject that is 'outside' my own sphere, because such "knowledge we seek cannot be gained solely or simply through introspection ${ }^{56}$." It is also true that as a filmmaker, I am connected in some ways to the subject matter I want to document. The degree of familiarity or intimacy with such a topic or group of persons, the length of time I have been in contact with them, and the different strands that interconnect us, are all-important aspects for the filmmaker to reflect upon. This self-reflection can help me find where to dig deeper within the film, while constituting a point of relevance to and critique of the social world I intend to inform and affect.

Therefore, for this documentary, I chose a reflexive ethnographic approach, which enabled a space for a negotiation between the filmmaker, the participants, and the audience. The filmmaker opts to speak "not only about the historical world but about the problems and issues of representing it as well ${ }^{57}$." Along these lines, the camera's powerful gaze comes to question its own capacity to represent or misrepresent the other.

\footnotetext{
55 Davies, Charlotte Aull. Reflexive Ethnography: A Guide to Researching Selves and Others (London: Routledge, 1999), Kindle edition.

56 Ibid.

57 Nichols, Bill. Introduction to Documentary (Bloomington, IN: Indiana University Press, 2001), 194.
} 
Nevertheless, "[f]ilmmaking as therapeutic discourse, like analysis, remains interminable, always unfinished ${ }^{58}$," while the camera unveils, reveals our desires and frustrations as in the surface of a time-lapse discursive mirror.

\subsubsection{Performativity}

Using speech to consummate an action or to construct and perform an identity, the documentary's participants uttered or inferred phrases such as: "I am not a girl, I am a boy." "Even though I was born a boy, I identify and socially perform as a girl." "I have no fixed gender; one day I act as a boy, another day as a girl;" or yet in another occasion, "I see myself as gender neutral." These statements constitute repeated actions of speech that become performative, reality transforming, and identity constructive.

If $\mathrm{I}$, as a documentalist, cross-dress for a screening and a Q\&A session of a documentary on the topic of gender, and declare I am doing so to support trans-gender individuals, I would be performing an activist representation. But if I iteratively do the same without making any comments on my self-representation, while it is obvious I am not a female, this would constitute a performative act, expressed through symbolic language.

We all perform diverse discursive acts in accordance with the ideals we have constructed within ourselves regarding gender roles. In some cases we behave in relation to how we socially embody the stereotypes we have learned during our infancy and adolescence. Such social practices that have been conditioned by the sex we were assigned at birth, our upbringing, socialization, cultural, and sexual interactions are also reified by our acts of speech or other expressions of language, constantly redefining whom we are.

58 Renov, Michael. The Subject of Documentary (Minneapolis: University of Minnesota Press, 2004), 222. 
Inserting the notion of performativity into my documentary informs the knowledge that is being shared during its production; it can "provide entry into an understanding of the general processes at work in society ${ }^{59}$." In other words, as the documentary was being made, a performance of experience and memory, of emotional involvement, affected not only the representational result on screen, but also how the actors and the film director may have been transformed by their participation in the film production and its dissemination.

\subsubsection{Participatory Dynamics}

This additional aspect, in which the filmmaker intervenes and interacts, overlaps with the previously covered notions of activism, reflexive ethnography, and performativity. In the production of this documentary, the filmmaker interacted with the subjects on the spot rather than merely observing them ${ }^{60}$. Moreover, the participants were invited to intervene in ways that modified the end result of the documentary. Interviews grew into conversations, and conversations had an impact on how the documentary was constructed, infusing it with an organic flow marked by collaboration (rather than confrontation). At some stage, these dynamics brought the director in front of the camera to be interviewed; although, this footage was not included in the final cut of the documentary.

Different levels and modes of participation I intended to include in this project, which did not happen or only partially, because of the time restrictions, are as follows:

- $\quad$ Children are encouraged to contribute ideas

- Children record aspects of the filming process and comment

- Children interview other children with their own electronic devices

- Parents interview their own children or the filmmaker

59 Nichols, Bill. Introduction to Documentary (Bloomington, IN: Indiana University Press, 2001), 201.
60 Ibid, 179. 
- $\quad$ Children interview the filmmaker

This mode of working would have given me the opportunity to get more thoroughly involved with the ethics and politics of the production encounter, which documentary theoretician Bill Nichols (2010) has expressed in the form of questions:

How do filmmaker and social actor respond to each other? Does a sense of respect, despite disagreement, emerge, or is there a feeling of deception, manipulation, distortion at work? How do they negotiate control and share responsibility? How much can the filmmaker insist on testimony when it is painful to provide it? What responsibility does the filmmaker have for the emotional aftermath of putting others on-camera? What goals join filmmaker and subject and what needs divide them ${ }^{61}$ ?

Giving some thought to these questions was important for me as a documentary filmmaker and as an interviewer who was "caught within oscillations between the familiar and the strange ${ }^{62}, "$ who worked with social actors whose personal matters may be painful to expose on-camera. Combining the notions of activism, participation, reflexivity, and performativity in a documentary multiplies the possibilities for the director and other participants to become mentors, critics, interrogators, collaborators, and provocateurs ${ }^{63}$, hopefully enriching the collaborative construction of a film that covers sensitive topics that will have an impact on everyone involved: the makers, the represented, and the audience.

\footnotetext{
61 Ibid, 182.

62 Nichols, Bill. Representing Reality: Issues and Concepts in Documentary. Bloomington: Indiana University Press, 199

63 Nichols, Bill. Introduction to Documentary (Bloomington, IN: Indiana University Press, 2001), 184.
} 


\section{Conclusion}

Documentary filmmaking, as I have adopted it, adds to the artistic educational practices I utilize as advocacy and activist tools. It helps me hone and re-articulate skills I use in every realm I imagine and perform as an activist. Documentary, in my opinion, is trivial if it does not reveal or address crucial topics related to the construction of healthier social systems and the preservation of nature. Increasing respect and awareness on human rights and diversity, according to my views, expands the possibilities for humans to learn how to harmonize and sustain a viable relationship with each other and with the environment itself. Nevertheless, considerable hurdles were encountered during the production of the documentary: I was not able to create deeper connections with my interviewees; nor could I create the piece I had intended, with wider participation of the subjects represented in the film; nor was it possible to follow the script of having a protagonist write a letter to politicians. Despite all these barriers, I feel satisfied with the organic flow of its development, resulting in a piece that ponders an ethics of care and covers an actual and controversial subject, while still entertaining, and hopefully, sensitizing and transforming an audience.

Word Count: 11,485 


\section{Works Cited}

Abedi, Maham. "Canada is 150 and still needs to face its racism problem: advocates." Global News. June 29, 2017. Accessed July 06, 2017.

http://globalnews.ca/news/3556823/racism-in-canada/.

Abramovich, Ilona Alex (2012). "No Safe Place to Go LGBT - Youth Homelessness in Canada: Reviewing the Literature." Canadian Journal of Family and Youth, University of Alberta, 4(1). 29-51

Alcoff, Linda Martín. "The Problem of Speaking For Others." The Problem of Speaking For Others $\mid$ Alcoff.com. 1994. Accessed November 17, 2016.

http://alcoff.com/content/speaothers.html.

Barney, D. D. (2003). Health risk-factors for gay American Indian and Alaska Native adolescent males. Journal of Homosexuality 46 (1), 137-157.

Bauer, G., Boyce, M., Coleman, T., Kaay, M., Scanlon, K., \& Travers, R. (2010). Who are trans people in Ontario? 1 (1) Toronto: Trans PULSE E-Bulletin. http://www.ohtn.on.ca/Documents/Publications /didyouknow/july28_10/EBulletin.pdf

Canada, Government Of Canada Statistics. "Police-reported hate crime in Canada, 2012." Government of Canada, Statistics Canada. November 30, 2015. Accessed June 18, 2017. http://www.statcan.gc.ca/pub/85-002-x/2014001/article/14028-eng.htm.

Canada, Government Of Canada Statistics. "Police-reported sexual offences against children and youth in Canada, 2012." Government of Canada, Statistics Canada. November 30, 2015. Accessed July 08, 2017. http://www.statcan.gc.ca/pub/85-002x/2014001/article/14008-eng.htm\#a9.

Coffee and Cigarettes. "Strange to Meet You." Directed by Jim Jarmusch. Performed by Roberto Benigni and Steven Wright. 2003. Accessed November 12, 2016. https://www.youtube.com/watch?v=ggqrEMtA3TU.

Cohen, Tobi. "Hate Crimes against Gays Doubled in Canada." Canwest News Service. Accessed October 22, 2016. http://www.canada.com/life/Hate crimes against gays doubled Canada/3155968/story.html.

Comstock, Gary David. Violence against lesbians and gay men. New York: Columbia University Press, 1991, 2.

Connell, Raewyn. Gender in World Perspective. Cambridge: Polity, 2009. Kindle.

Cowan, G., Heiple, B., Marquez, C., Khatchadourian, D., \& McNevin, M. (2005). Heterosexuals' attitudes toward hate crimes and hate speech against gays and lesbians: Old fashioned and modern heterosexism. Journal of Homosexuality, 49 (2), 67-82 
Chandler, M. J., \& Lalonde, C. (1998). Cultural continuity as a hedge against suicide in Canada's first nations. Transcultural Psychiatry, 35, 191-219.

Daniels, Joe Parkin. "Tackling Teenage Pregnancy in Colombia." The Lancet. April 18, 2015. Vol.385, No.9977, 1495-1496. Accessed July 06, 2017.

http://www.thelancet.com/journals/lancet/article/PIIS0140-6736(15)60738-3/fulltext.

Davies, Charlotte Aull. Reflexive Ethnography: A Guide to Researching Selves and Others. London: Routledge, 1999, Kindle edition.

DiAngelo, Robin. "No, I Won't Stop Saying." YES! Magazine. June 30, 2017.

Accessed July 02, 2017. http://www.yesmagazine.org/people-power/no-i-wont-stopsaying-white-supremacy-20170630.

D'Augelli, A. R., Hershberger, S. L., \& Pilkington, N. W. (2001). Suicidality patterns and sexual orientation-related factors among lesbian, gay, and bisexual youths. Suicide and Life-Threatening Behavior 31 (3), 250-265.

Dreyfus, Hubert L. From the Repressive Hypothesis to Bio-Power. In Hubert L. Dreyfus and Paul Rainbow, eds. Michel Foucault: Beyond Structuralism and Hermeneutics. Chicago: University of Chicago Press 1983.

Eagle Canada. "Hate Crimes Targeting LGBT Community Remain Most Violent in Canada." April 12, 2012. Accessed February 1, 2017.

Eisler, Riane Tennenhaus. Sacred Pleasure: Sex, Myth, and the Politics of the Body. San Francisco, CA: HarperSan Francisco, 1995.

Evans, Mary, and Carolyn Williams. Gender: The Key Concepts. Abingdon, Oxon: Routledge, 2013, Kindle edition.

"Feminism and Gender." New World Encyclopedia. Accessed October 18, 2016. http://www.newworldencyclopedia.org/entry/Gender.

Gilligan, Carol. "Ethics of Care." 2015. Accessed November 29, 2016.

http://ethicsofcare.org/carol-gilligan/.

Gómez, Camilo. "Girls and Boys Who Make Boys and Girls." FUNDACIÓN LINTERNA. 2013. Accessed November 28, 2016.

http://www.fundacionlinterna.org/english/proyectos.html.

Gómez, Camilo. "Gris-gris Contre L'abus." CAMILO GOMEZ-DURAN PHOTOGRAPHE - FOTOGRAFO - PHOTOGRAPER. 2010. Accessed November 14, 2016. http://www.camilogomezduran.com/p_gri.html.

Gómez, Camilo. "Sacred Flow." FUNDACIÓN LINTERNA. 2013. Accessed November 28, 2016. http://www.fundacionlinterna.org/english/proyectos.html.

Government of Canada, Department of Justice, Research and Statistics Division. "Victims of Crime Research Digest, Issue No. 2, 2009." Government of Canada, 
Department of Justice, Research and Statistics Division. January 07, 2015. Accessed July 08, 2017. http://www.justice.gc.ca/eng/rp-pr/cj-jp/victim/rd09_2-rr09_2/p3.html.

Just. "Textilism and Nudophobia." January 2008. Accessed July 03, 2017. http://boards1.melodysoft.com/app?ID=addan\&msg=788.

Krishna, Rau. "Lesbian, Gay, Bisexual and Transgender Rights in Canada." The Canadian Encyclopedia. June 16, 2014. Accessed October 28, 2016.

http://www.encyclopediecanadienne.ca/en/article/lesbian-gay-bisexual-andtransgender-rights-in-canada/.

Lindsey, Linda L., and Sandra Christie. Gender Roles: A Sociological Perspective. Upper Saddle River, N.J: Prentice Hall, 1997

Mattson, S. R. (2012). Growing up gay or bisexual: The experiences of young gay and bisexual men in Windsor and Essex County, Ontario. (Unpublished Ph.D. dissertation). Windsor, ON: University of Windsor.

Middlehurst, Steve. "Context and Narrative." Notes for Assesor. January 17, 2016. Accessed November 23, 2016. https://stevemiddlehurstcontextandnarrative.wordpress.com/.

Money, J. "Psychologic Approach to Psychosexual Misidentity with Elective Mutism: Sex Reassignment in Two Cases of Hyperadrenocortical Hermaphroditism." Clinical Pediatrics 7, no. 6 (1968): 331-39. Accessed October 18, 2016. doi:10.1177/000992286800700608.

Nichols, Bill. Introduction to Documentary Bloomington, IN: Indiana University Press, 2001.

Nichols, Bill. Representing Reality: Issues and Concepts in Documentary. Bloomington: Indiana University Press, 1991.

Nuttbrock, L., Hwahng, S., Bockting, W., Rosenblum, A., Mason, M., Macri, M., \& Becker, J. (2010). Psychiatric impact of gender-related abuse across the life course of male-to-female transgender persons. Journal of Sex Research 47 (1), 12-23.

Rainbow Health Ontario. RHO Fact Sheet: LGBTQ Youth Suicide, 2015. Accessed October 19. doi:10.1075/ps.5.3.02chi.audio.2f.

Rees, Emma L. E. The Vagina: A Literary and Cultural History. New York: Bloomsbury Academic, 2013.

Renov, Michael. The Subject of Documentary (Minneapolis: University of Minnesota Press, 2004.

Steiner, Wendy. The Scandal of Pleasure: Art in an Age of Fundamentalism. Chicago: University of Chicago Press, 1995.

Super Size Me. Directed by Morgan Spurlock. 2004. 
Takeuchi, Craig. "Hate Crimes in Canada: Most Violent against Gays, Black People Most Targeted Racial Group." Straight Talk. June 27, 2014. Accessed October 25, 2016. http://www.straight.com/news/675221/hate-crimes-canada-most-violentagainst-gays-black-people-most-targeted-racial-group.

Taylor, C., \& Peter, T. (2011). Every class in every school: Final report on the first national climate survey on homophobia, biphobia, and transphobia in canadian schools. Toronto, ON: Egale Canadian Human Rights Trust.

http://archive.egale.ca/EgaleFinalReport-web.pdf

Tencer, Daniel. "Student Debt Is Rising, And Mental Health Problems Are Rising With It." HuffPost Canada. May 30, 2016. Accessed July 03, 2017. http://www.huffingtonpost.ca/2016/05/30/student-debt-mentalhealth_n_10208520.html.

The Mahabharata. Directed by Peter Brook. 1989. Accessed October 15, 2016. https://www.youtube.com/watch?v=EENh1hxkD6E.

The Mask You Live In. Directed by Jennifer Siebel. Performed by Carolyn Heldman. Accessed December 2015. http://therepresentationproject.org/film/the-mask-you-livein/.

Tworek, Heidi. "The Real Reason the Humanities Are 'in Crisis"" The Atlantic.

December 18, 2013. Accessed November 29, 2016.

http://www.theatlantic.com/education/archive/2013/12/the-real-reason-thehumanities-are-in-crisis/282441/.

"Understanding and Addressing Violence Against Women." 2012. Accessed July 03, 2017. http://apps.who.int/iris/bitstream/10665/77421/1/WHO_RHR_12.38_eng.pdf.

"Violence against women, sexual violence, women, abuse, discrimination, Elimination of Violence against Women." United Nations. Accessed June 29, 2017. http://www.un.org/en/events/endviolenceday/. 